\title{
Pain and Depression in Gynecology Patients
}

\author{
Ellen L. Poleshuck ${ }^{1,2}$, Matthew J. Bair ${ }^{3}$, Kurt Kroenke ${ }^{4}$, Arthur Watts ${ }^{2}$, Xin Tu ${ }^{2}$, and Donna \\ E. Giles ${ }^{2}$ \\ ${ }^{1}$ Wynne Center for Family Research, Rochester, NY \\ 2University of Rochester School of Medicine and Dentistry, Rochester, NY \\ ${ }^{3}$ Roudebush VA Center of Excellence on Implementing Evidence Based Practice, Indianapolis, IN \\ ${ }^{4}$ Indiana University School of Medicine, Indianapolis, IN
}

\section{Abstract}

The prevalence and consequences of comorbid pain and depression in gynecology patients are understudied. Self-reported pain, depressive symptoms, other mental disorder symptoms, functional status, interpersonal distress, and abuse were assessed in 1647 gynecology patients using the Patient Health Questionnaire and the Medical Outcomes Study SF-20. Moderate to severe pain was reported by $29 \%$ of patients and depression by $21 \%$, with both present in $10.3 \%$. Comorbid pain and depression was associated with anxiety, suicidal or death ideation, functional impairment, interpersonal distress, and physical or sexual abuse. Innovative approaches are needed to assess and treat gynecology patients with comorbid pain and depression.

Depressive disorders are a leading cause of disability in the US ${ }^{1}$ and are common in obstetric and gynecology settings, ranging from $4 \%-22 \% .^{2-4}$ Chronic pain is also highly prevalent and disabling, representing the most common somatic symptom among primary care patients. ${ }^{5}$ Limited research shows that the prevalence of pain ranges from $25 \%$ to $36 \%$ among female primary care and women's health patients. ${ }^{6 ; 7}$ While uncertainty remains regarding the underlying mechanisms linking pain and depression, individuals with chronic pain are at increased risk for depression, and individuals with depression are at increased risk for chronic pain. ${ }^{6 ; 8-10}$ Further, patients with pain and depression experience a more severe clinical course and poorer outcomes of both conditions. ${ }^{8}$ Gynecological settings are the sole source of primary care for many women. ${ }^{11 ; 12}$ The prevalence and consequences of comorbid pain and depression among women in gynecology settings, however, remain unknown.

Pain and depression are each frequently associated with comorbid mental disorders, impaired social functioning, and decreased quality of life. For example, anxiety disorders, substance use disorders, and suicide are all more likely among patients with either pain ${ }^{13-15}$ or depression. 16-19 Individually, pain ${ }^{20 ; 21}$ and depression ${ }^{22}$ are each associated with impaired function and disability. Women with both pain and depression are likely to have even greater functional impairments than those with pain or depression only. Lastly, abuse, impaired social function, and limited social support are associated with both pain $^{7 ; 23-28}$ and depression. ${ }^{7 ; 29-32}$ These interpersonal variables add to patient complexity by increasing treatment needs and interfering with effective engagement in treatment for their pain and depression.

There are gender differences in the report of both pain and depression. Women are more likely to report chronic pain than men. ${ }^{33-35}$ Women report more severe pain for the same degree of

For reprints and correspondence, please contact: Ellen L. Poleshuck, Ph.D., University of Rochester Medical Center, 300 Crittenden Boulevard, Rochester, NY 14642, Phone: 585-275-3138, Ellen_Poleshuck@URMC.Rochester.edu. 
pathology, ${ }^{36}$ more pain sites (i.e. back, head, abdomen and others), $37 ; 38$ and are more likely to use analgesics to relieve their pain compared to men. ${ }^{39}$ Women are also more vulnerable to developing depression than men, with a lifetime prevalence of $21.3 \%$ compared to $12.7 \%$ in men. ${ }^{16}$ Finally, women are more likely to report emotional distress associated with their pain.

${ }^{40}$ Understanding the factors associated with comorbid pain and depression is critical to developing comprehensive and individualized assessments and treatments.

The purpose of this study was to determine the prevalence of pain, depression, and their cooccurrence among gynecology patients, and to examine how pain and depression are associated with additional comorbid mental disorders, reduced level of functioning, and interpersonal stress and abuse. The ultimate aim is to improve the recognition of women with these conditions and to identify new inroads into comprehensive and integrated treatments for women with comorbid pain and depression.

\section{Method}

\section{Sites and selection of participants}

Data were collected as part of a descriptive validation and utility study of the Primary Care Evaluation of Mental Disorders Patient Health Questionnaire (PHQ) with Obstetric/ Gynecological (Ob/Gyn) patients. The Medical Outcomes Study Short-Form General Health Survey (SF-20) was administered to all participants as well. The complete research protocol has been described previously. ${ }^{3}$ Briefly, data were collected from March 1997 through March 1999 at seven ambulatory Ob/Gyn sites, which were diverse in geography, racial/ethnic mix, and education of patients served. The protocol was approved by all institutional review boards.

While waiting to see their health care providers for routine visits, participants completed the study questionnaires. Each study site used one of two sampling methods: either consecutive patients or every $n t h$ patient in a given clinic session was approached until the intended quota for the session was achieved. Of the 3,636 women $\geq$ age 18 approached to participate at the seven Ob/Gyn sites, 245 declined, 127 did not complete the questionnaire (usually due to limited time before seeing their provider), and 320 had missing data and were not analyzed, yielding a total of 2,944 participants for analysis. Pregnant and postpartum patients $(n=992)$ were excluded from the current study because they represent a unique population in terms of pain and potential treatments. An additional 305 women did not report their pregnancy status, and were dropped from the analyses. Thus, a total of 1,647 questionnaires were analyzed. Twenty-seven percent of the participants completed the questionnaires in Spanish.

\section{Measures}

Depression-The Patient Health Questionnaire (PHQ), a self-administered version of the Primary Care Evaluation of Mental Disorders (PRIME-MD) ${ }^{41}$ that assesses common psychiatric diagnoses based on DSM-IV ${ }^{42}$ criteria, was used to measure depression. The diagnostic validity and reliability of the PHQ has been established in 3,000 primary care and 3,000 Ob/Gyn patients. $3 ; 41$ The PHQ includes items that correspond to DSM-IV criteria of four disorders: major depression, panic disorder, other anxiety disorder, and bulimia nervosa. The PHQ also assesses four disorders designated as "subthreshold" for meeting full DSM-IV criteria: other depressive disorder, probable alcohol abuse or dependence, binge-eating disorder, and somatoform disorder. Patients who met criteria for major depression or other depressive disorder were classified as depressed $(0=$ not depressed, $1=$ depressed $)$. For depression, the PHQ has $61 \%$ sensitivity and $94 \%$ specificity compared to the original clinician-administered PRIME-MD. ${ }^{41}$ 
Pain-The SF-20 encompasses assessment of health-related quality of life in six domains: pain, social, role, emotional, mental, and physical functioning. ${ }^{44}$ The single item on pain severity was used to measure pain: "In the last 4 weeks, how much bodily pain have you had?" To aid analysis and interpretability of results, participants' responses were dichotomized as "low pain" (none, very mild, or mild pain $=0$ ) or "high pain" (moderate, severe, and very severe pain $=1)$.

Co-morbid mental disorders-The PHQ was used to assess anxiety disorder, alcohol abuse, and eating disorder in addition to depression. Patients who met PHQ criteria for either panic disorder or other anxiety disorder, and either bulimia nervosa or binge-eating disorder, were classified as having the disorder $(=1)$. Those who did not meet threshold or subthreshold criteria were classified as not having the disorder $(=0)$. The PHQ has $63 \%$ sensitivity and $97 \%$ specificity for anxiety disorder, and $89 \%$ sensitivity and $73 \%$ specificity for eating disorder when compared to the original clinician-administered PRIME-MD. ${ }^{41}$ Somatoform disorder was excluded because clinical judgment to evaluate a biological explanation of the participant's physical symptoms was not done.

Level of functioning -Interference with activities was measured with the PHQ item assessing number of days in the past 3 months ( 0 to 90 days) the participant did not participate in her usual activities for health reasons. Role functioning was assessed with the SF-20 subscale. Suicidal and death ideation was measured by the single PHQ item: "Over the last 2 weeks how often have you been bothered by thoughts that you would be better off dead, or of hurting yourself in some way?" Possible responses included: "not at all," "several days," "more than half the days," and "nearly every day" (0-3). Social functioning was measured using the SF-20 subscale.

Interpersonal stress and abuse-Our version of the PHQ for women includes items about physical or sexual abuse in the past year and 10 common psychosocial stressors that may have occurred in the last month (e.g. work stress, relationship conflict, financial problems). Interpersonal stress was measured by summing 3 items (range 0 to 30, with higher scores representing more stress): 1) difficulties with husband/wife, partner/lover or boyfriend/ girlfriend; 2) stress of taking care of children, parents, or other family members; and 3) having no one to turn to when you have a problem (Cronbach's alpha=0.61, $\mathrm{SE}=0.02)$. Abuse was measured by a single dichotomous item on the PHQ: "In the last year, have you been hit, slapped, kicked or otherwise physically hurt by someone, or has anyone forced you to have an unwanted sexual act?" (0/1).

\section{Data Analysis}

Data were analyzed using SPSS for Windows, version 15.0. Descriptive statistics characterized the overall sample and prevalence of pain, depression, and comorbid pain and depression. Means and standard deviations were estimated for continuous descriptive variables and outcome measures. Frequencies and percentages were used for categorical variables. Multiple linear and logistic regression analyses tested direct effects of pain, depression, and their interactions, in predicting the dependent variables: interpersonal stress, quality of life, and comorbid mental disorders. Regression analyses were adjusted for age, race/ethnicity, education, marital status, language of survey administration, and clinic site. 


\section{Results}

\section{Sample description}

Patients had a mean (SD) age of 33.1 (11.3) years, with a range of 18-97 years (Table 1). Racial and ethnic distributions were: $41.5 \%$ White (non-Hispanic), 37.2\% Hispanic, 17.2\% African American, and $4.2 \%$ other. Race, ethnicity and educational level varied substantially by site (Hispanic ethnicity, 1-81\%; African American, $<1 \%$ to $21 \%$; college graduate, 2-61\%). Most (76.9\%) completed high school or greater and half were married or partnered $(50.4 \%)$.

\section{Prevalence of Pain and Depression}

A total of $29.1 \%$ of patients $(n=479)$ reported moderate, severe, or very severe pain ("high pain" group) in the past 4 weeks, and $21.1 \%(\mathrm{n}=348)$ met criteria for depression (PHQ major depression and/or PHQ other depression). Of the 479 patients with high pain, 35.3\% ( $\mathrm{n}=169)$ also had depression. Of the 348 patients with depression, 48.6\% $(n=169)$ also had high pain. For the overall sample, $10.3 \%(\mathrm{n}=169)$ reported both high pain and depression. Prevalence of mental disorders and abuse and means of functional status and interpersonal stress by pain and depression status are summarized in Table 2.

\section{Comorbid Mental Disorders}

Multiple logistic regression analyses determined the independent effects of depression and pain on the likelihood of mental disorders (Table 3). The strongest association was with anxiety disorders, which were much more likely in patients with depression $(\mathrm{OR}=18.9, \mathrm{CI}=12.2$ to 28.6 ) and pain ( $\mathrm{OR}=4.5, \mathrm{CI}=3.0$ to 6.7$)$. Depression, but not pain, was also significantly associated with alcohol abuse and eating disorders.

\section{Level of functioning}

Multiple regression models were also used to predict functioning based on depression and pain status (Table 4). Depression and pain were both associated with decrements in role functioning, social functioning, suicidal or death ideation, and interference with usual activities for health reasons in the past 3 months, although depression was more strongly associated with all four outcomes. The variance accounted for by the combination of pain and depression ranged from $10 \%$ to $24 \%$.

\section{Interpersonal stress and abuse}

We used multiple regression models to predict interpersonal stress based on depression and pain status adjusting for covariates (Table 4). Again, the presence of depression and pain both were independently associated with greater interpersonal stress in the past 4 weeks and, with $23 \%$ variance accounted for by pain and depression. Depression was more highly associated than pain with interpersonal stress.

Because abuse in the past year chronologically preceded self-report of pain and depression, we modeled abuse status as a predictor of pain and depression rather than using pain and depression to predict abuse. In two separate multiple regression analyses adjusted for demographics, language and site, abuse in the past year was associated with pain ( $O R=19.8$, $C I: .18, .52, p<.01)$ and depression $(O R=27.6, C I: .12, .37, p<.01)$.

\section{Interactions}

The interaction between pain and depression in each regression analysis was tested to assess their multiplicative impact. Only the significant interactions are reported. Adjusting for demographics, site, and language of administration, there were 3 significant interactions between depression and pain in predicting eating disorders $(p<.01)$, suicidal or death ideation 
$(p<.01)$, and number of interference days $(p<.05)$. Women with comorbid pain and depression were statistically more likely (32.5\%) to report more suicidal and death ideation than those with pain $(3.0 \%)$ or depression (30.2\%) alone. Similarity in absolute rates of suicidal and death ideation in the two groups with depression suggest that pain contributes, yet in a relatively minor way, to thoughts of death and dying. The combination of pain and depression was also associated with more interference days (11.3 days) than pain alone (3.9 days) or depression alone (5.4 days). In contrast, high depression in the absence of pain was associated with a higher prevalence of eating disorders than high depression/high pain and either of the low depression conditions. While the interaction between pain and depression was significant for eating disorders, the relatively low prevalence of eating disorders in our sample make these estimates unreliable. Additionally, women with both pain and depression more frequently reported physical or sexual abuse in the past year $(13 \%, \mathrm{n}=21)$ compared to women with pain alone $(5 \%, \mathrm{n}=15)$ and depression alone $(8.5 \%, \mathrm{n}=15)(\mathrm{p}<.01)$.

\section{Discussion}

Many women use their women's health practitioner as their main source for primary care. ${ }^{2 ;}$

${ }^{11}$ In our study, approximately one in ten women presenting for routine gynecological care reported comorbid pain and depression. Significant pain was present in $49 \%$ of women with depression, and depression was present in $35 \%$ of women with high levels of pain. These results are similar to prevalence rates in other primary care settings. ${ }^{8: 43}$ Gynecology clinics serve as important access points for the assessment and treatment of women with complex and debilitating health problems such as comorbid pain and depression.

Anxiety disorders were found to be highly prevalent among women with comorbid pain and depression. Depression increased the odds of an anxiety disorder by nineteen times, and pain increased the likelihood by four and a half. These findings support Kroenke and colleagues $^{\prime 45}$ recent study demonstrating that anxiety disorders are prevalent and often undetected in primary care, and that there are relationships between anxiety disorders, depression, and somatic symptoms such as pain. It is essential to evaluate anxiety among gynecology patients with pain and depression. Yet the complicated symptom presentation of this patient population may interfere with detection of anxiety disorders. Brief new screening tools for anxiety are available to simplify detection. ${ }^{45 ; 46}$ In contrast to anxiety disorders, depression, but not pain, was associated with increased prevalence of eating disorders and alcohol abuse or dependence. It is unclear why high depression and low pain status would be associated with increased risk of eating disorders in our sample, but given the small number of women in this sample with eating disorders, these findings should be interpreted with caution. Based on our findings, women with comorbid pain and depression may not be at specific risk compared to women with depression alone for alcohol abuse or dependence or eating disorders.

Risk for suicidal and death ideation was significantly increased among women with pain and depression. More specifically, approximately one-third of women with comorbid pain and depression reported frequent suicidal or death ideation in the past two weeks. Given that both depression ${ }^{19}$ and pain ${ }^{15}$ are independent risk factors for suicide, it is especially important that providers conduct safety assessments of patients with both conditions.

The decreased role functioning and reduced ability to participate in daily activities evidenced by the women with pain and depression in this sample underscores the pervasive impact of their symptoms. Furthermore, this combination of symptoms may directly impede patients' ability to engage in and adhere to care. For example, women with pain and depression reported missing an average of 11.3 days of their usual activities in the past 3 months. As a result, it 
may be particularly difficult for them to attend scheduled appointments consistently, increasing risk for poor clinical outcomes.

The association between comorbid pain and depression and impaired interpersonal functioning may have implications for treatment engagement, planning, adherence, and outcomes. For example, if a woman is in a violent relationship or has very limited social support, she may focus on these issues rather than management of her pain symptoms, despite her physical suffering. Comprehensive and integrated treatments that are attentive to contextual issues such as personal safety and relationship functioning may help address some of the complex needs of women with comorbid pain and depression. Interpersonal therapy is a promising treatment in this context. Interpersonal therapy is effective for depressed women with childhood abuse histories ${ }^{47}$ and with comorbid physical and mental health concerns. ${ }^{48-50}$ Future work should investigate the effectiveness of interpersonal therapy for women with comorbid pain and depression.

A few limitations deserve mention. First, standardized diagnostic interviews, rather than selfreport data, would provide a more precise assessment of psychiatric diagnoses. Second, information about pain duration or interference and current or previous treatments for pain or depression is unknown. Third, socioeconomic status was not assessed, so its contribution to pain and depression could not be considered. Fourth, the cross-sectional design of the study cannot address causality.

In sum, comorbid pain and depression was common among gynecology patients and associated with anxiety disorder, suicidal ideation, poor functioning, interpersonal stress, and recent abuse. These findings extend our knowledge of the relationship between pain and depression to patients in gynecology clinic settings, and introduce consideration of interpersonal functioning. Optimal assessment and treatment of comorbid pain and depression in gynecology settings is a priority area in women's health.

\section{Acknowledgments}

Portions of this paper were presented at the 2006 meeting of the American Pain Society meeting. Supported in part by NIMH grants T32 MH018911 and K23 MH079348. We gratefully acknowledge the contributions of the Wynne Center for the Family, Yan Ma, Ph.D., and Lacy Morgan, B.S.

\section{References}

1. Published by the Harvard School of Public Health on behalf of the World Health Organization and the World Bank. , editor. Summary: The global burden of disease: a comprehensive assessment of mortality and disability from diseases, injuries, and risk factors in 1990 and projected to 2020. Cambridge, MA: Harvard University Press; 1996.

2. Miranda J, Azocar F, Komaromy M, Golding JM. Unmet mental health needs of women in publicsector gynecologic clinics. Am J Obstet Gynecol 1998;178(2):212-217. [PubMed: 9500476]

3. Spitzer RL, Williams JBW, Kroenke K, Hornyak R, McMurray J. Validity and utility of the PRIMEMD Patient Health Questionnaire in assessment of 3000 obstetric-gynecologic patients: The PRIMEMD Patient Health Questionnaire Obstetrics Gynecology Study. Am J Obstet and Gynecol 2000;183 (3):759-769. [PubMed: 10992206]

4. Scholle S, Haskett R, Hanusa B, Pincus H, Kupfer D. Addressing depression in obstetrics/gynecology practice. Gen Hosp Psychiatry 2003;25:83-90. [PubMed: 12676420]

5. Kroenke K, Mangelsdorff AD. Common symptoms in ambulatory care - Incidence, evaluation, therapy, and outcome. Am J Med 1989;86(3):262-266. [PubMed: 2919607]

6. Gureje O, Simon GE, Von Korff M. A cross-national study of the course of persistent pain in primary care. Pain 2001;92(12):195-200. [PubMed: 11323140] 
7. Poleshuck EL, Giles DE, Tu X. Pain and depressive symptoms among financially disadvantaged women's health patients. J Womens Health 2006;15(2):182-193.

8. Bair MJ, Robinson RL, Katon W, Kroenke K. Depression and pain comorbidity - A literature review. Arch Intern Med 2003;163(20):2433-2445. [PubMed: 14609780]

9. Moldin SO, Scheftner WA, Rice JP, Nelson E, Knesevich MA, Akiskal H. Association between major depressive disorder and physical illness. Psychol Med 1993;23(3):755-761. [PubMed: 8234581]

10. Gureje O, Von Korff M, Simon GE, Gater R. Persistent pain and well-being: A World Health Organization study in primary care. JAMA 1998;280(2):147-151. [PubMed: 9669787]

11. Scholle SH, Kelleher K. Assessing primary care performance in an obstetrics/gynecology clinic. Women \& Health 2003;37(1):15-30.

12. Weisman C, Cassard S, Plichta S. Types of physicians used by women for regular health care: Implications for services received. J Womens Health 1995;4:407-416.

13. Sareen J, Cox BJ, Clara I, Asmundson GJG. The relationship between anxiety disorders and physical disorders in the US National Comorbidity Survey. Depress Anxiety 2005;21(4):193-202. [PubMed: 16075453]

14. Latthe P, Mignini L, Gray R, Hills R, Khan K. Factors predisposing women to chronic pelvic pain: Systematic review. BMJ 2006;332(7544):749-751. [PubMed: 16484239]

15. Fishbain DA. The association of chronic pain and suicide. Semin Clin Neuropsychiatry 1999;4:221227. [PubMed: 10498789]

16. Kessler RC, Mcgonagle KA, Zhao SY, Nelson CB, Hughes M, Eshleman S, Wittchen HU, Kendler KS. Lifetime and 12-month prevalence of DSM-III-R psychiatric-disorders in the United-States Results from the National-Comorbidity-Survey. Arch Gen Psychiatry 1994;51(1):8-19. [PubMed: 8279933]

17. Regier DA, Farmer ME, Rae DS, Locke BZ, Keith SJ, Judd LL, Goodwin FK. Comorbidity of mentaldisorders with alcohol and other drug-abuse - Results from the Epidemiologic Catchment-Area Study. JAMA 1990;264(19):2511-2518. [PubMed: 2232018]

18. Gorman JM, Coplan JD. Comorbidity of depression and panic disorder. J Clin Psychiatry 1996;57:3443. [PubMed: 8917130]

19. Bronisch T. The relationship between suicidality and depression. Arch Suicide Res 1996;2(4):235254.

20. Centers for Disease Control. MMWR Morb Mortal Wkly Rep. Vol. 50. 2001. p. 120-125.

21. Mounce K. Back pain. Rheumatology 2002;41(1):1-5A. [PubMed: 11792871]

22. Stover E, Fenton W, Rosenfeld A, Insel T. Depression and comorbid mental illness: The National Institute of Mental Health perspective. Biological Psychiatry 2003;54:184-186. [PubMed: 12893092]

23. Peat G, Thomas E, Handy J, Croft P. Social networks and pain interference with daily activities in middle and old age. Pain 2004;112(3):397-405. [PubMed: 15561396]

24. Lim HJ, Lee MS, Lim HS. Exercise, pain, perceived family support, and quality of life in Korean patients with ankylosing spondylitis. Psychol Rep 2005;96(1):3-8. [PubMed: 15825897]

25. Dekkers JC, Geenen R, Evers AWM, Kraaimaat FW, Bijlsma JWJ, Godaert GLR. Biopsychosocial mediators and moderators of stress-health relationships in patients with recently diagnosed rheumatoid arthritis. Arthritis Rheum 2001;45(4):307-316. [PubMed: 11501717]

26. Kerns RD, Haythornthwaite JA. Depression among chronic pain patients - Cognitive behavioralanalysis and effect on rehabilitation outcome. J Consult Clin Psychol 1988;56(6):870-876. [PubMed: 3204197]

27. Kerns RD, Turk DC. Depression and Chronic Pain - The mediating role of the spouse. J Marriage Fam 1984;46(4):845-852.

28. Poleshuck E, Dworkin R, Howard F, Foster D, Shields C, Tu X. Multidimensional assessment of the roles of physical and sexual abuse in women with chronic pelvic pain. J Reprod Med 2005;50(2): 91-100. [PubMed: 15755045]

29. Scholle SH, Rost KM, Golding JM. Physical abuse among depressed women. J Gen Intern Med 1998;13(9):607-613. [PubMed: 9754516] 
30. Kovac SH, Klapow JC, Kroenke K, Spitzer RL, Williams JB. Differing symptoms of abused versus nonabused women in obstetric-gynecology settings. Am J Obstet Gynecol 2003;188(3):707-713. [PubMed: 12634645]

31. Boyce P, Harris M, Silove D, Morgan A, Wilhelm K, Hadzi-Pavlovic D. Psychosocial factors associated with depression: A study of socially disadvantaged women with young children. J Nerv Ment Dis 1998;186(1):3-11. [PubMed: 9457141]

32. Wade TD, Kendler KS. The relationship between social support and major depression - Crosssectional, longitudinal, and genetic perspectives. J Nerv Ment Dis 2000;188(5):251-258. [PubMed: 10830561]

33. Meana M. The meeting of pain and depression: Comorbidity in women. Can J Psychiatry 1998;43 (9):893-899. [PubMed: 9825159]

34. Gachtel, RJ.; Turk, DC., editors. The role of sex and gender in pain perception and responses to treatment, in Psychosocial Factors in Pain: Critical Perspectives. New York: The Guilford Press; 1999. p. 401-411.

35. Gachtel, RJ.; Turk, DC., editors. Sociocultural and religious meanings of pain, in Psychosocial Factors in Pain: Critical Perspectives. New York: The Guilford Press; 1999. p. 118-131.

36. Moulin DE, Foley KM, Ebers GC. Pain syndromes in multiple-sclerosis. Neurology 1988;38(12): 1830-1834. [PubMed: 2973568]

37. Andersson HI, Ejlertsson G, Leden I, Rosenberg C. Chronic pain in a geographically defined generalpopulation - Studies of differences in age, gender, social-class, and pain localization. Clin J Pain 1993;9(3):174-182. [PubMed: 8219517]

38. Lester N, Lefebvre JC, Keefe FJ. Pain in young-adults: I. Relationship to gender and family pain history. Clin J Pain 1994;10(4):282-289. [PubMed: 7858357]

39. Eggen AE. The Tromso Study - Frequency and predicting factors of analgesic drug-use in a freeliving population (12-56 years). J Clin Epidemiol 1993;46(11):1297-1304. [PubMed: 8229107]

40. Fillingim, R., editor. Psychosocial contributions to sex-related differences in pain responses, in Sex, Gender, and Pain: Progress in Pain Research and Management. Washington: IASP Press; 2000. p. 41-68.

41. Spitzer RL, Kroenke K, Williams J. Validation and utility of a self-report version of PRIME-MD: The PHQ primary care study. JAMA 1999;282:1737-1744. [PubMed: 10568646]

42. American Psychiatric Association. Diagnostic and Statistical Manual of Mental Disorders. 4. Washington: American Psychiatric Association; 1994.

43. Arnow BA, Hunkeler EM, Blasey CM, Lee J, Constantino MJ, Fireman B, Kraemer HC, Dea R, Robinson R, Hayward C. Comorbid depression, chronic pain, and disability in primary care. Psychosom Med 2006;68(2):262-268. [PubMed: 16554392]

44. Ware JE. Scales for measuring general health perceptions. Health Services Research 1976;11:396415. [PubMed: 1030696]

45. Kroenke K, Spitzer RL, Williams J, Monahan PO, Lowe B. Anxiety disorders in primary care: Prevalence, impairment, comorbidity, and detection. Ann Intern Med 2007;146:317-325. [PubMed: 17339617]

46. Spitzer RL, Kroenke K, Williams JBW, Lowe B. A brief measure for assessing generalized anxiety disorder - The GAD-7. Arch Intern Med 2006;166:1092-1097. [PubMed: 16717171]

47. Talbot NL, Conwell Y, O'Hara MW, Stuart S, Ward EA, Gamble SA, Watts A, Tu X. Interpersonal psychotherapy for depressed women with sexual abuse histories - A pilot study in a community mental health center. J Nerv Ment Dis 2005;193(12):847-850. [PubMed: 16319710]

48. Koszychi D, Lafontaine S, Frasure-Smith N, Swenson R, Lesperance F. An open-label trial of interpersonal psychotherapy in depressed patients with coronary disease. Psychosomatics 2004;45 (4):319-324. [PubMed: 15232046]

49. Markowitz JC, Kocsis JH, Fishman B, Spielman LA, Jacobsberg LB, Frances AJ, Klerman GL, Perry SW. Treatment of depressive symptoms in human immunodeficiency virus-positive patients. Arch Gen Psychiatry 1998;55(5):452-457. [PubMed: 9596048]

50. Karp JF, Weiner D, Seligman K, Butters M, Miller M, Frank E, Stack J, Mulsant BH, Pollock B, Dew MA, Kupfer DJ, Reynolds CF. Body pain and treatment response in late-life depression. Am J Geriatr Psychiatry 2005;13(3):188-194. [PubMed: 15728749] 


\section{Table 1}

Sample Description

\begin{tabular}{|c|c|c|c|c|}
\hline & Mean & SD & Range & $\mathbf{n}$ \\
\hline Age & 32.9 & 11.2 & $18-97$ & 1647 \\
\hline Demographic and Clinical Distributions & & $\%$ & & $\mathrm{n}$ \\
\hline \multicolumn{5}{|l|}{ Race } \\
\hline Caucasian & & 41.5 & & 687 \\
\hline Hispanic & & 37.2 & & 616 \\
\hline African American & & 17.2 & & 285 \\
\hline Other & & 1.8 & & 29 \\
\hline Missing & & 1.8 & & 30 \\
\hline \multicolumn{5}{|l|}{ Education } \\
\hline $8^{\text {th }}$ grade or less & & 8.2 & & 135 \\
\hline Some high school & & 14.8 & & 243 \\
\hline High school graduate & & 29.0 & & 478 \\
\hline Some college & & 26.5 & & 437 \\
\hline College graduate or higher & & 21.4 & & 353 \\
\hline Missing & & 0.1 & & 1 \\
\hline \multicolumn{5}{|l|}{ Marital Status } \\
\hline Married & & 50.4 & & 830 \\
\hline Never married & & 32.2 & & 530 \\
\hline Separated/Widowed/Divorce & & 17.4 & & 287 \\
\hline High pain (moderate, severe or very severe) & & 29.1 & & 479 \\
\hline Depressive disorder & & 21.1 & & 348 \\
\hline High pain and depressive disorder & & 10.3 & & 169 \\
\hline
\end{tabular}


堷

कี

g.

के

ฝี

ลั

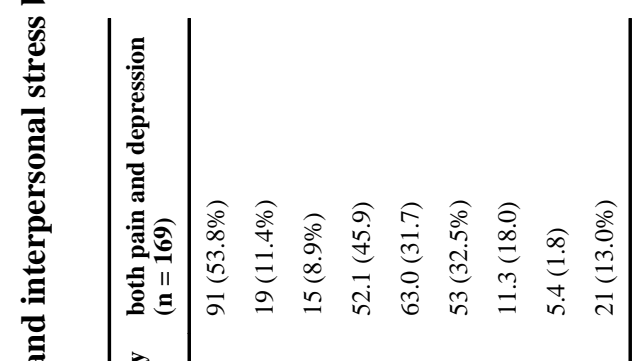

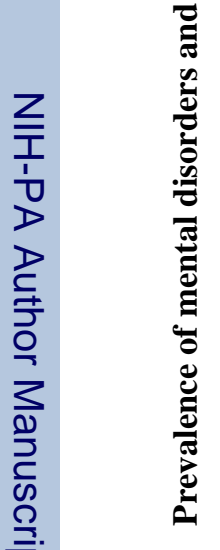

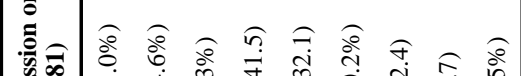

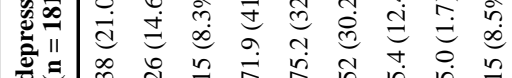

은

훙

这

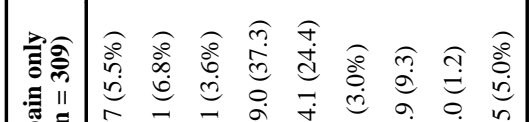

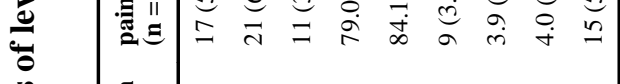

๘

흔

要

Ð్

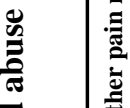



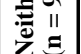

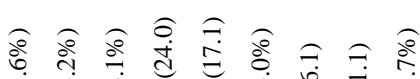

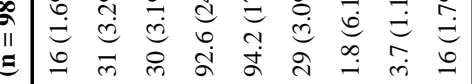

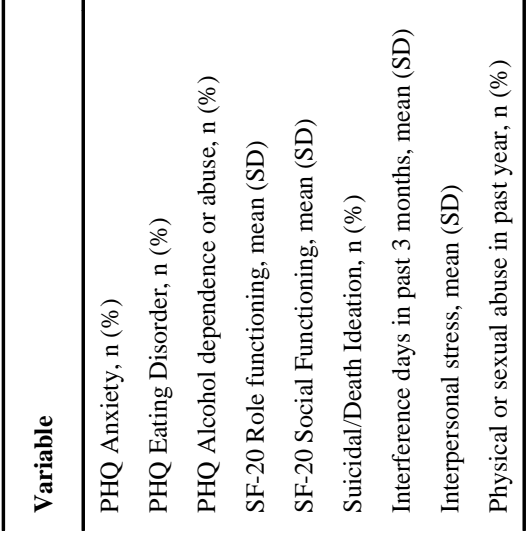

Psychosomatics. Author manuscript; available in PMC 2010 May 1. 


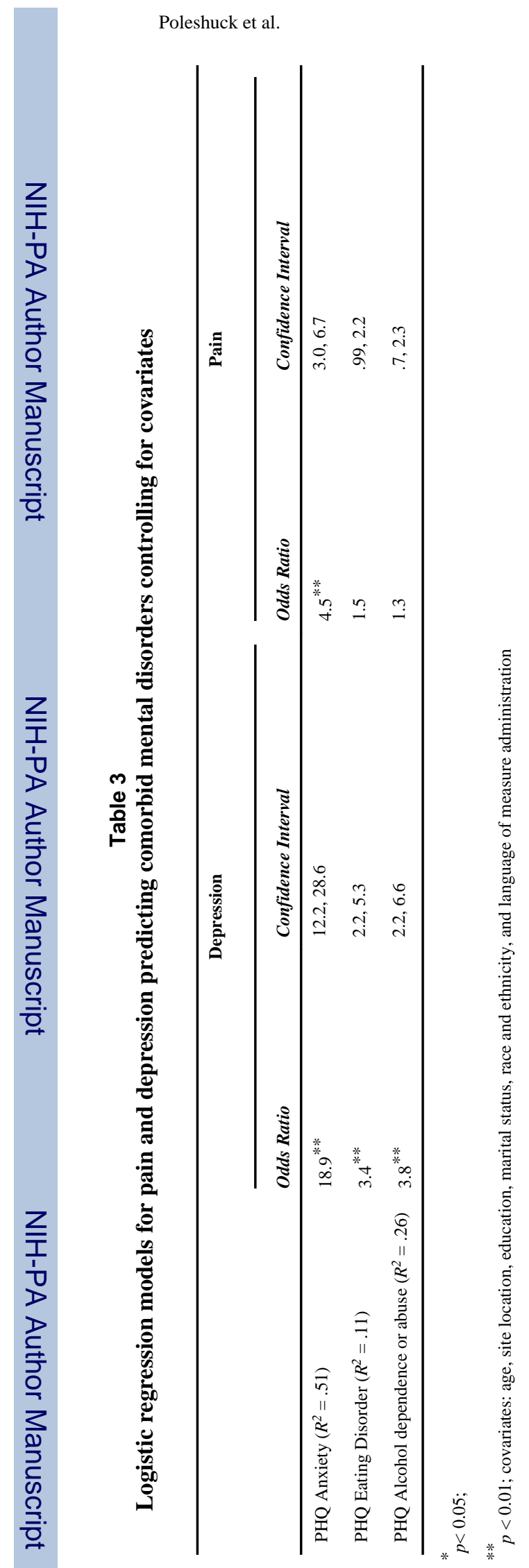

Psychosomatics. Author manuscript; available in PMC 2010 May 1. 


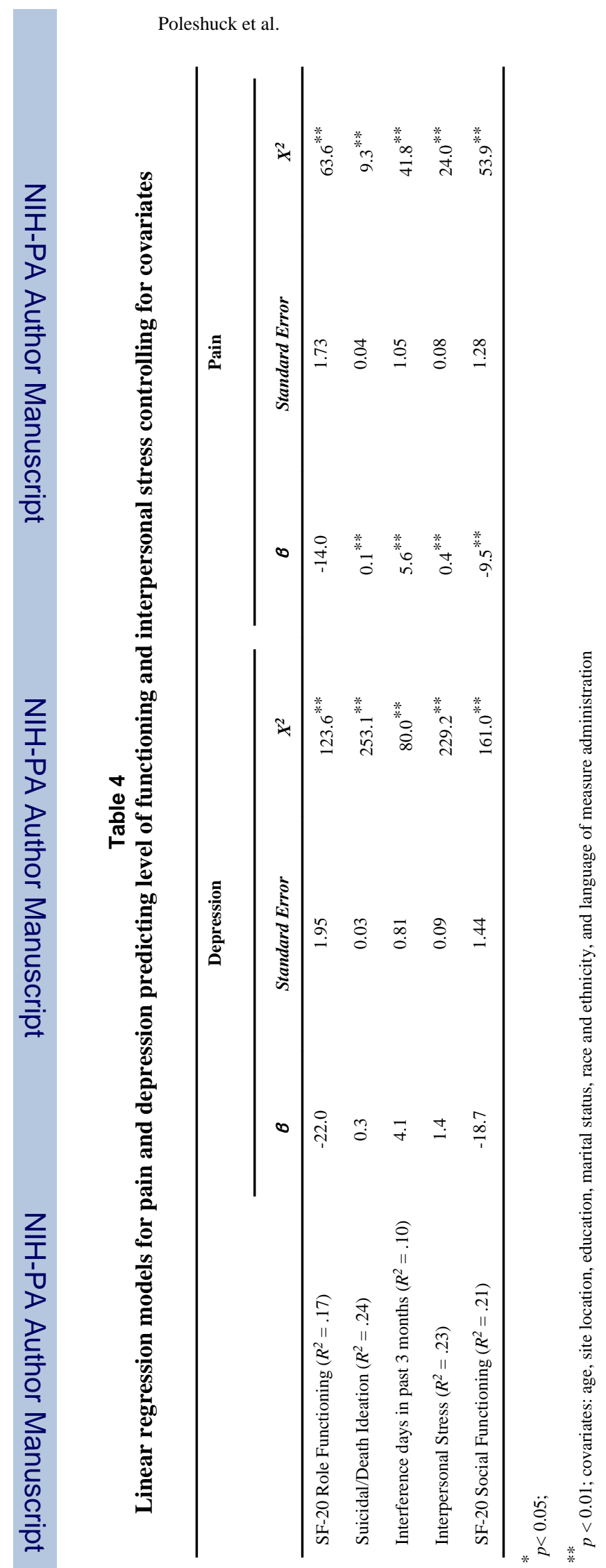

Psychosomatics. Author manuscript; available in PMC 2010 May 1. 